\title{
A recurrent missense mutation in the LPAR6 gene underlies hereditary hypotrichosis
}

\author{
Zarlashta Sharif ${ }^{1}$, Sheikh Ahmed ${ }^{1}$, Fazal ur Rehman ${ }^{2}$, Ashif Sajjad ${ }^{1}$ and \\ Muhammad Ayub ${ }^{*}$ \\ 1. Institute of Biochemistry, Faculty of Life Sciences, University of Baluchistan, Quetta-Pakistan \\ 2. Department of Microbiology, Faculty of Life Sciences, University of Baluchistan, Quetta-Pakistan \\ *Corresponding author's email: ayub_2004@hotmail.com \\ Citation \\ Zarlashta Sharif, Sheikh Ahmed, Fazal ur Rehman, Ashif Sajjad and Muhammad Ayub. A recurrent missense \\ mutation in the LPAR6 gene underlies hereditary hypotrichosis. Pure and Applied Biology. Vol. 6, Issue 2, pp685- \\ 690. http://dx.doi.org/10.19045/bspab.2017.60072
}

Received: 04/03/2017

Revised: 19/05/2017

Accepted: $28 / 05 / 2017$

Online First: 02/06/2017

\section{Abstract}

Hypotrichosis is a heritable condition described by sparse hairs, sparse to absent eyebrows, eyelashes, axillary, and body hair, but with normal teeth and nails. Genotyping was carried out of family from fourth generation from district Sibi, Balochistan, having two affected males and one female. Genotyping was done targeting LPAR6-linked microsatellite markers present on chromosome 13q14.11-q21.32. The exon located on LPAR6 gene, were amplified of both affected and normal individuals of the family revealing linkage at locus on chromosome 13. Sequencing result of the LPAR6, shown a recurrent missense mutation c.436G>A, p. G146R) in a family. A recurrent missense mutation revealed in the current investigation encompass the evidence of LPAR6 gene hereditary hypotrichosis.

Keywords: Hereditary hypotrichosis; LPAR6 gene; Missense mutation

\section{Introduction}

The word hypotrichosis describes an-inborn malformations of the hair on scalp, eyelashes and eyebrows but the affected individuals have normal teeth and nails. Genetically hypotrichosis is an autosomal recessive, autosomal dominant X-linked inheritance. Seven autosomal recessive hypotrichosis genes have been identified including four responsible for autosomal dominant hypotrichosis. It has been revealed only recently that autosomal recessive hypotrichosis is caused by the mutation in either LIPH or LPAR6 gene [1]. LIPH and LPAR6 codes for proteins involved in the synthesis of fundamental component of cell membranes "2-acyl-lysophosphatidic acid" and oleoyl-Lalpha-Lysophodphatidic acid (LPA) which serves as ligand for the P2Y5 a G-protein-coupled receptor (GPCR) [2].

The expression of LPAR6 gene take place in innermost part of hair follicle [3-5] and together with LIPH gene is convoluted in differentiation and regulation of hair growth cycle [6].

LARP6 coded protein consists of La motif (LAM) and a RNA recognition motif (RRM) and are implicated in regulating translation and maturation of tRNAs [7, 8]. LARP6 coded protein is also linked with the 
formation of vimentin intermediate filaments, non-muscle myosin filaments, helicase A, serine-threonine kinase receptor-associated protein (STRAP) and binding FK506 protein 3 (FKBP3) [9, 10]. LPAR6 (MIM No. 609239) coded protein P2Y5 play an important role in the regulation and maturation of hair follicles [11]. LPAR6 gene consists of one exon with ORF coding for 344 amino acids [12] with 7 hydrophobic transmembrane, 4 extracellular and 4 cytoplasmic domains. (http:// au.expasy.org/uniport/p4367). P2Y5 protein in combination with different fatty acids play key role in apoptosis, muscle contraction and cell migration [12].

Several type mutations in LPAR6 gene have already been identified, including missense, nonsense, insertion, deletion and frame shift mutations [11]. Novel (if any) or recurrent mutation in LPAR6 gene would increase the spectrum of the known mutations, emphasizing the role of GPCR together with LIPH in regulating hair growth cycle $[2,13]$. Materials and methods Patients

With the consent of elders of the family, family history was taken (Figure 1). The blood samples were collected from both normal and affected individuals in EDTAcontaining tubes. Genomic DNA was extracted from the affected and normal individuals in the human molecular genetics lab institute of Biochemistry, UOB, Quetta. The patients were examined at the civil hospital sibi, Balochistan and the study was approved by the Institutional Review Board, University of Balochistan, Quetta, Pakistan.

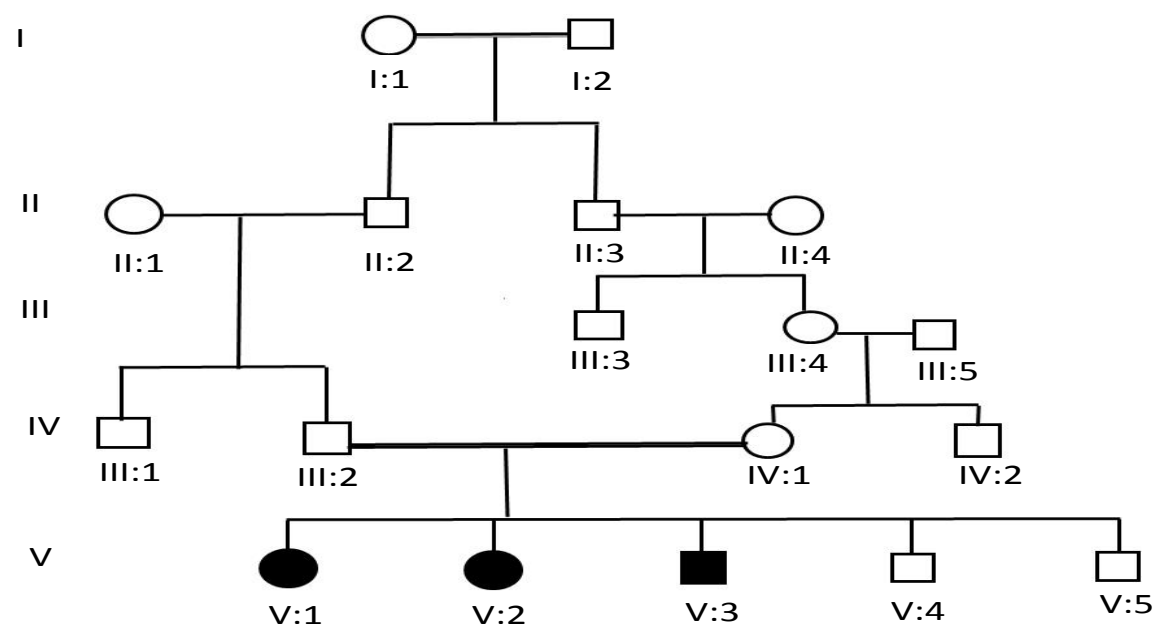

Figure 1. Pedigree of Family form Sibi district, affected with hereditary hypotrichosis. Squares and circles designate males and females respectively. The double line indicates cousin marriages while, the shaded squares show the affected male and circles shaded black indicate female

\section{Results}

\section{Clinical features}

In the present study, a family was enrolled with phenotypic hereditary Hypotrichosis characterized by sparse hair on the scalp, sparse eyelashes \& eyebrows, however they have a normal teeth and nails (Figure 2). 


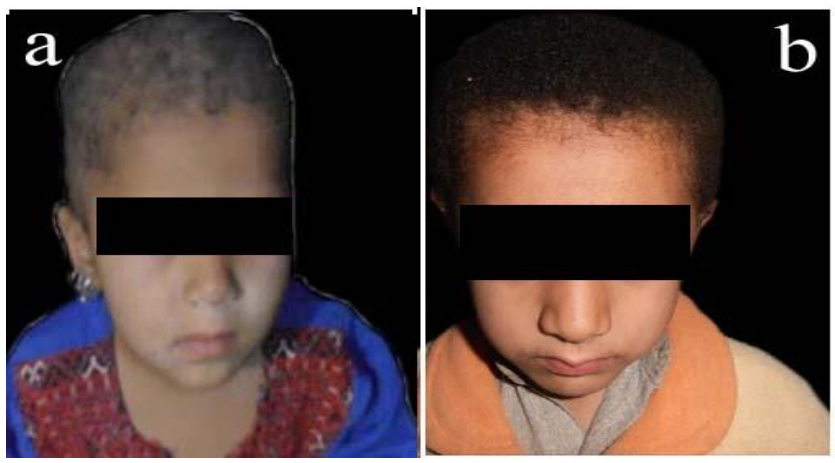

Figure 2. Medical findings in the existing family with hereditary hypotrichosis (a) the phenotypic of affected male and female (IV-1), (IV-3) presenting, sparse hairs, eyebrows, eyelashes, and body hair with normal teeth and nails

\section{Mutation analysis}

The exon-intron boundaries LPR6 gene was amplified using pacific primers by PCR and the product was sequenced, using the ABI Prism Big Dye Terminator Cycle Sequencing Ready Reaction Kit (PE Applied Biosystems) in Automated Sequencer.
Sequencing result of the family showed recurrent missense mutation in both LPAR6/P2RY5 gene designated as c.436G>A, p. G146R) which was absent in 100 Pakistani family individuals analyzed (Figure 3). The mutation was predicted, harmful with following statistical score of 0.993 (Figure 4).

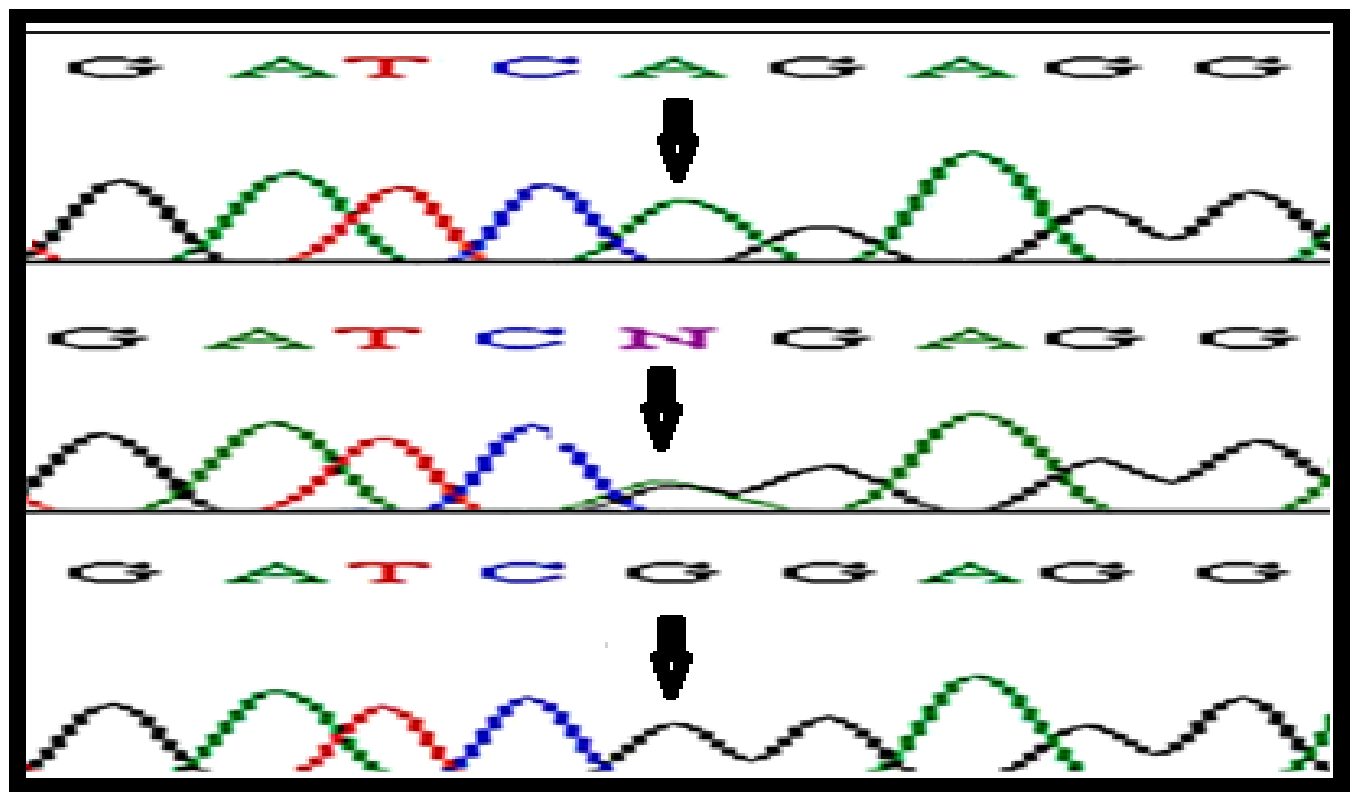

Figure 3. P2RY5 gene sequence analysis in family with LAH3.

DNA sequence from a homozygous (affected) individuals presenting a transition (G>A), a heterozygous carrier and a phenotypically normal individuals showing wild type sequence. The arrow indicates site of mutation 


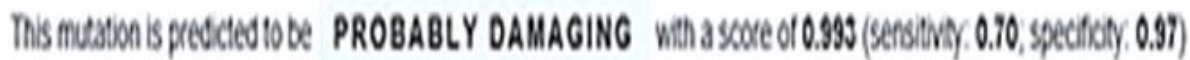

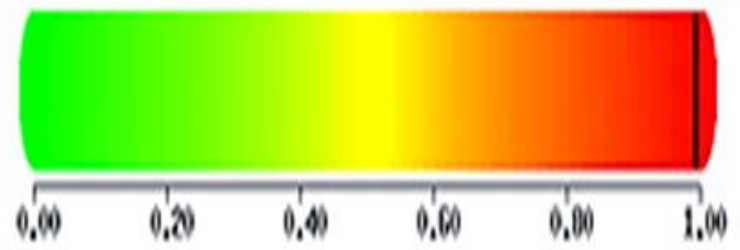

Figure 4. PolyPhen-2 analysis of recurrent missense mutation in affected family. The color bar with the black indicator demonstrating the strength of the presumed damaging effect for the variant with statistical score of 0.993

\section{Discussion}

For the current study, an extremely consanguineous family was enrolled, representing hypotrichosis from distric sibi situated in the east of Balochistan. Genetic disorder was inborn in the family members and the manner of inheritance was autosomal recessive. The affected individuals of the family showed, sparse hairs, sparse to absent eyebrows, eyelashes, axillary, and body hair (Figure 2). The family was tested for linkage by typing highly polymorphic microsatellite markers linked to already known loci including hypotrichosis (3q26.33-q27.2), LIPH, LAPR6(13q12.11), corneodesmosin on chromosome (6p21.33), hairless gene (8p21), desmoglin and desmocolin (18q12.1).

The family linked to the LAH3 locus on chromosome 13. The abnormal individuals in the family showed sparse hair on the scalp, eyebrows, eyelashes, axillary and body hair, however affected individuals were having normal teeth and nails. The phenotype woolyhair has already been reported by Shimomura [14].

Until now, a different mutation has been identified in LAPR6 producing LAH3 phenotype; e.g. missense mutation, frame shift-mutation and stop at codon. We have reported a recurrent missense mutation in a family with hereditary hypotrichosis, designated c.436G>A, p. G146R). This mutation was predicted to be probably harmful with a statistical score of 0.993 .

This LAPR6 gene consists of one exon with an open reading frame (ORF) coding a protein (P2Y5) comprising of 344 amino acids and belongs to G-protein coupled receptors (GPCR) activated by adenosine and uridine nucleotides [12]. LAPR6 gene is expressed in epidermis and innermost layer of hair follicle playing a significant role in the maintenance of hair growth cycle and quality [15, 16]. P2Y5 is a G-protein coupled receptor comprising of seven hydrophobic trans membrane helices, four cytoplasmic, and four potentially extracellular helices (http:// au.expasy.org/uniprot/P43657) [5] P2Y5 is a GPCR which bind extracellular nucleotides as ligands moreover Pasternack et al. reported oleoyl-Lalpha-lysophosphatidic acid (LPA) is a bioactive lipid composed of several fatty acids engaged in several processes including cellular proliferation, migration of cell, contraction and apoptosis [15].

\section{Conclusion}

A pathogenic mutation identified in the present research work extends the body of 
proof implicating the LPAR6 gene in hereditary hypotrichosis emphasizing the role of GPCR together with LIPH in regulating hair growth cycle.

\section{Authors' contributions}

Conceived and designed the experiments: $M$ Ayub, Performed the Experiments: Z Sharif, Analyzed the Data: FU Rehman, Contributed reagents/ materials/ analysis tools: S Ahmed \& A Sajjad, Wrote the paper: Z Sharif.

\section{Acknowledgments}

We thank members of the family involved in the study for their invaluable participation and cooperation. We also thank Higher Education Commission (HEC), Islamabad, Pakistan for their financial support for the study.

\section{Reference}

1. Inoue A, Arima N \& Ishiguro J (2011). LPA-producing enzyme PA-PLAalpha regulates hair follicle development by modulating EGFR signalling. EMBO J 30: 4248-4260.

2. Jelani M, Wasif N, Ali G, Chishti MS \& Ahmad W (2008). A novel deletion mutation in $L I P H$ gene causes autosomal recessive hypotrichosis (LAH2). Clin Genet 74: 184-188

3. Kazantseva A, Goltsov A, Zinchenko R, Grigorenko AP, Abrukova AV, Moliaka YK, Kirillov AG, Guo Z, Lyle S, Ginter EK \& Rogaev EI (2006). Human hair growth deficiency is linked to a genetic defect in the phospholipase gene $L I P H$. Science 314: 982-985

4. Shimomura Y, Wajid M, Ishii Y, Shapiro L, Petukhova L, Gordon D \& Christiano AM (2008). Disruption of P2RY5, an orphan $G$ protein-coupled receptor, underlies autosomal recessive woolly hair. Nat Genet 40: 335-339

5. Webb TE, Kaplan MG \& Barnard EA (1996). Identification of $6 \mathrm{H} 1$ as a P2Y purinoceptor: P2Y5. Biochem Biophys Res Commun 219: 105-110
6. Pasternack SM, Murugusundram S, Eigelshoven S, Müller M, Kruse R, Lehmann P \& Betz RC (2009). Novel mutations in the P2RY5 gene in one Turkish and two Indian patients presenting with hypotrichosis and woolly hair. Arch Dermatol Res 301: 621-624

7. Stavraka C \& Blagden S (2015). The La-related proteins, a family with connections to cancer. Biomolecules 5(4): 2701-2722.

8. Bousquet-Antonelli C \& Deragon JM (2015). A comprehensive analysis of the La-motif protein superfamily. RNA. 2009; 15(5): 750-764.

9. Cai L, Fritz D, Stefanovic L \& Stefanovic B (2010). Nonmuscle myosin-dependent synthesis of type I collagen. $J$ Mol Biol 401(4): 564-578.

10. Manojlovic Z, Blackmon J \& Stefanovic B (2010). Tacrolimus (FK506) prevents early stages of ethanol induced hepatic fibrosis by targeting LARP6 dependent mechanism of collagen synthesis. PLoS ONE. 2013. 8(6): e65897.

11. Shinkuma S, Akiyama $M$ \& Inoue A (2010). Prevalent LIPH founder mutations lead to loss of P2Y5 activation ability of PA-PLA1alpha in autosomal recessive hypotrichosis. Hum Mutat 31: 602-610.

12. Herzog H, Darby K, Hort YJ \& Shine J (1996). Intron 17 of the human retinoblastoma susceptibility gene encodes an actively transcribed $G$ protein-coupled receptor gene. Genome Res 6: 858-861.

13. Kazantseva A, Goltsov A, Zinchenko R, Grigorenko AP, Abrukova AV, Moliaka YK, Kirillov AG, Guo Z, Lyle S, Ginter EK \& Rogaev EI (2006). Human hair growth deficiency is linked to a genetic defect in the phospholipase gene LIPH. Science 314: 982-985.

14. Shimomura Y, Garzon MC, Kristal L, Shapiro L \& Christiano AM (2009). 
Autosomal recessive woolly hair with hypotrichosis caused by a novel homozygous mutation in the $P 2 R Y 5$ gene. Exp Dermatol 18: 218-2211.

15. Pasternack SM, von Kügelgen I, Aboud KA, Lee YA, Rüschendorf F, Voss K, Hillmer AM, Molderings GJ, Franz T, Ramirez A, Nürnberg P, Nöthen MM \& Betz RC (2008). G protein-coupled receptor P2Y5 and its ligand LPA are involved in maintenance of human hair growth. Nat Genet 40: 329-334.

16. Shimomura Y, Wajid M, Petukhova L, Shapiro L \& Christiano AM (2009). Mutations in the Lipase H (LIPH) gene underlie autosomal recessive woolly hair/hypotrichosis. $J$ Invest Dermatol 129: 622-628. 